\title{
Design of the Humidity and Temperature Controller Using the Moistures of Leaf and Soil
}

\author{
Walaa Kareem Khalaf ${ }^{1,2 *}$, Yong Tae $\mathrm{Kim}^{3}$ \\ ${ }^{1}$ Graduated School of International Development and Cooperation, Hankyong National University, Anseong 17579, Republic \\ of Korea \\ ${ }^{2}$ Ministry of Agriculture, State Company for Agricultural Supplies, Baghdad 10061, Iraq \\ ${ }^{3}$ Department of Electrical, Electronics and Control Engineering, Hankyong National University, Anseong 17579, Republic of \\ Korea
}

Corresponding Author Email: walaakareem79@gmail.com

https://doi.org/10.18280/ijdne.160409

Received: 3 May 2021

Accepted: 8 June 2021

\section{Keywords:}

leaf moisture, soil moisture, humidity and temperature, greenhouse, arduino Uno

\begin{abstract}
A controlling of air temperature and humidity is important issue because environment change has effects on growing stages of plants. In this study a (DHT22, AH-300u, YL69) sensors and a microcontroller (arduino Uno) have been used to monitoring and controlling the temperature, humidity of air and control irrigation process based on monitoring the moistures of (soil, plant leaf) data inside the greenhouse prototype. The findings during the experiment time (4 days) indicates that the air temperature maintain at reference value $27^{\circ} \mathrm{C}$ and relative humidity has a slightly increase by 0.7 from reference value (82). The output voltage of soil moisture sensor has been monitor at a small range $(0.8 \mathrm{v}-1 \mathrm{v})$ roughly stable, and it is near to field capacity. The output voltage of leaf moisture sensor is slightly increased. From this study it has been observed that the proposed system in a greenhouse is a good procedure to maintain air temperature and humidity inside the greenhouses and effective for monitoring air factors as well as soil and leaf moistures. regarding irrigation process, a decision table has been suggested to control the irrigation water flow rate according to output voltage of each of soil and leaf moistures sensors.
\end{abstract}

\section{INTRODUCTION}

A controlling environment is one of Progression of technology which plays a main factor in our life especially in agricultural field, where many of greenhouses are normal constructions with polyethylene cover without systems to control climate which result increase possibilities of plants affect to pests and fungal diseases, un getting of optimum growth and productivity. Also, the using technique of ventilation to manage air humidity temperature, which are, in most condition, far from optimality and dependent on the outside air variables - which resulting in relatively low yields $[1,2]$. The Protected agriculture proposed as one way to improve agricultural output by protecting the crops from harsh weather conditions and pests and diseases [3] if implemented well with using intelligent technology. Controlling of protected agriculture environment systems will help in ensuring food security as a proactive measure for the expected increasing in the world's population, which will reach 9.6 billion on year 2050. According to Jenson et al. [4] protected agriculture is "the modification of the natural environment to achieve optimum plant growth.", and Control may impose on air carbon dioxide, humidity, temperature, light, water, plant nutrients alongside with complete climatic protection. In other hand, monitoring of smart environments can be defined as a completed task for a set of measured parameters, dynamic processes and static values [5,6]. And a detune of measured system can be made from each variable to put the system in regulated fixed process [7-9]. Smart agriculture has the following properties [10]: Monitoring of plant condition by using sensors, controlling farmland remotely, controlling environmental conditions inside greenhouse as needed, estimation of the optimal conditions for plants according to data collected. Air conditioning play a major rule in modification and controlling natural environment in smart agriculture as the American society of heating, refrigerating and air conditioning engineers (ASHRAE) defines air conditioning as: "A process of treating air to control its humidity, temperature, distribution, cleanliness simultaneously to meet the requirements of the conditioned space.". In enclosed space, smart air conditioning has fastacting microprocessor-based controls to control humidity, temperature, air movement and an indoor climate to meet any required and comfortable conditions, high year-round operation, system flexibility and easy service result from a desirable combination of temperature, humidity, air movement and air cleanliness. Vapor pressure deficit (VPD) is more accurate to specifying the loss of water from the plant. If the VDP is high then vapor pressure inside the plant is higher than the outside air, which results more water vapor transferred out through the Stomata's. Regarding the leaf moisture content, it exists either within cell or on its surface and affect transpiration and plant consumption for water.

The dielectric constant of a leaf is a function of water content and frequency [11]. Irrigation frequency is typically based on a predetermined schedule or visual evaluation of plant water status [12] and this may lead to overwatering, which causes leaching and runoff. Volumetric water content 
(VWC) may be the most useful measurement for automating irrigation systems [13]. Capacitance sensors allow for easy automation [14] and such automated irrigation is reliable [15] and can be used with a variety of container sizes [16] and irrigation systems. This study was carried out to solve the problems of high cost of air conditioning processes in greenhouse if they work without controlling, un controlled Temperature result in plant stress that limits growth and yield, un controlled humidity causes plants to infect with pests and fungal diseases, water deficiency brings about low quality and quantity of crop yield, over-irrigation causes low water use efficiency and low plant resistance to water shortage increasing the damages.

The study purpose to measure, display, control air temperature and humidity, which results controlling in air moisture content and vapor pressure deficit in greenhouse.

The second purpose to monitoring the Leaf and soil moistures levels as an output voltage of sensors in order to control the irrigation process.

\section{RELATED STUDIES}

Shock and Wang [17] concluded that the controlled environment provided effective cooling and humidity reduction, whereas the non-controlled environment elevated ambient temperature and humidity conditions. Plant growth parameters (height, stem diameter and leaf surface area) within the CEA greenhouse were much greater than those for the naturally ventilated greenhouse.

Suraj et al. [18] gave a model with a relatively simple and suitable estimation of maize leaf moisture content by measuring dielectric constant, and a generalized precise model can be developed to estimate leaf water content and employed to recognize water stress and time of irrigation in real-time mode without damaging the plants.

Afzal and Mousavi [19] discussed and analyzed variation of sensor analog voltage and capacitance with water add to soil.

It has been noticed that analog voltage and capacitance follow a linear pattern with water addition; also, it is able to monitoring soil moisture and reducing irrigation time.

Mander and Arora [20] concluded that the using of Arduino MC Platform is an ideal way for similar non-industrial automations implementation, and there is ability to manage a large range of actuators through handle multiple sensors at low cost.

\section{MATERIALS AND METHODS}

\subsection{Greenhouse prototype}

A closed prototype greenhouses with one door construct and place in laboratory covered with agricultural polyethylene film (see Figure 1), an air fan fixed with it and other experimental devices inside the prototype, the specifications illustrated in Table 1.

Table 1. Specifications of greenhouse prototype

\begin{tabular}{cc}
\hline Construction material & wood \\
\hline Size $(\mathbf{L} \times \mathbf{W} \times \mathbf{H})$ & $2 \mathrm{~m} \times 1.5 \mathrm{~m} \times 2 \mathrm{~m}$ \\
\hline Covering details & Cover type: polyethylene cover \\
\hline Cover thickness & $0.16 \mathrm{~mm}$ (double layers) \\
\hline
\end{tabular}

\subsubsection{The plant and soil used in experiment}

In this study Two of maize plants are use in experiment, type (Zea mays L. VSCO3) aged 26 days, transplanted in two well - drained pots, each pot has dimensions (upper diameter base $24.5 \mathrm{~cm}$, lower diameter base $18.5 \mathrm{~cm}$, height $21 \mathrm{~cm}$ ), and filled with soil (mixing ratio 3 sand: 1 clay: 1 organic clay), soil volume $0.0059 \mathrm{~m}^{3}$.

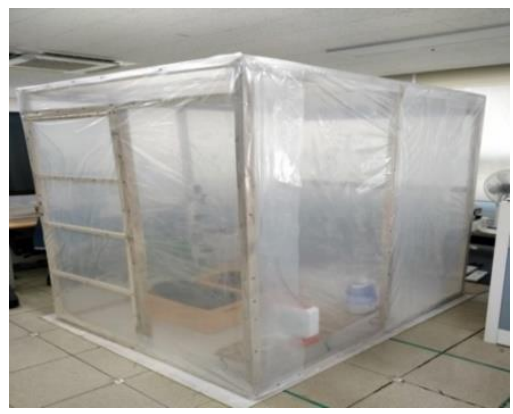

Figure 1. Greenhouse Prototype

\subsection{Hardware system}

\subsubsection{System sensors}

Temperature and humidity sensor DHT22. A low-cost sensor, with a high-precision measurement, simple to use, excellent quality, strong anti-jamming capability, fast response, small size and low power consumption, model type AM2303, operating voltage (DC) 3.3-5.5 volt, temperature measuring range $-40^{\circ} \mathrm{C} \sim 80^{\circ} \mathrm{C}$, relative humidity measuring range $0 \% \mathrm{RH} \sim 99.9 \% \mathrm{RH}$. It uses a capacitive humidity sensor and a thermistor temperature sensor to measure the surrounding air and connected with a high-performance 8-bit microcontroller with a digital signal on the data pin (Figure 2a), sensor readings up to 2 seconds old (sampling period).

Figure $2 b$ illustrate DHT22 sensor working during the experiment.

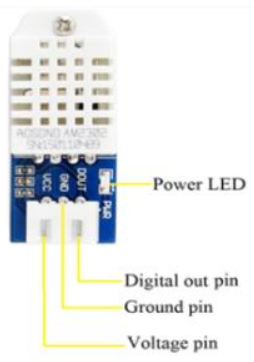

(a)

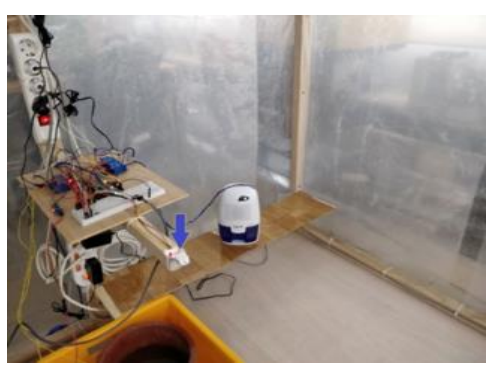

(b)
Figure 2. Temperature and Humidity Sensor DHT22

Soil moisture sensor YL-69. Used to measure the level of soil moisture (water content) at the time when other factors (air temperature, air relative humidity) were controlled and monitoring during the process, working on the principle of capacitance to measure dielectric permittivity of soil, dielectric permittivity is a function of soil moisture (water content). If the soil having shortage of water (dry soil) then the output of module is at high value; else in case of wet soil the output is at low value.

The output voltage of sensor is proportional to the dielectric permittivity, and therefore the water content of the soil. 
The soil moisture sensor is used to measure the loss of moisture level over time due to evaporation and plant uptake, also can be used to control irrigation in greenhouses by monitoring soil moisture content.

Figure 3 a illustrated the soil moisture sensor YL-69, while Figure $3 \mathrm{~b}$ showed the sensor in action during experiment.

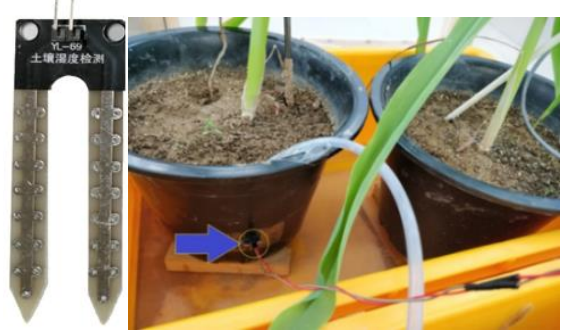

(a)

(b)

Figure 3. Soil moisture sensor YL-69

Leaf moisture sensor REV3. Improved -Calibrated realtime sensor AH-300u (see Figure 4a); that sensing water levels of live plants leaf through Affixing simply to the leaf of plant and start monitoring the indirect measurement of moisture level (see Figure 4b).

This sensor has a new improved electronics and clip, obtain real-time readings with a multimeter or data logger including Arduino devices and open source code, Watering lowers the voltage reading, when the voltage goes up its time to water, the sensor is self-calibration upon removal from the leaf.

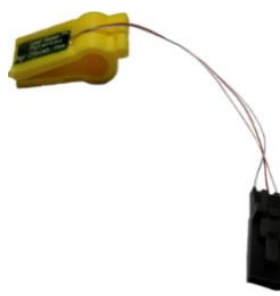

(a)

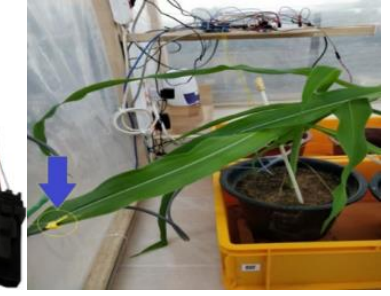

(b)
Figure 4. Leaf sensor $\mathrm{AH}-300 \mathrm{u}$

\subsubsection{System devices}

Arduino UNO REV3. It is a microcontroller (MC) board (open-source electronics platform) based on the ATmega328P.

It consists of 14 digital pins (input/output), 6 PWM output pins, 6 analog inputs pins, USB plug, ICSP header, a power supply socket and a reset button in Figure 5a.

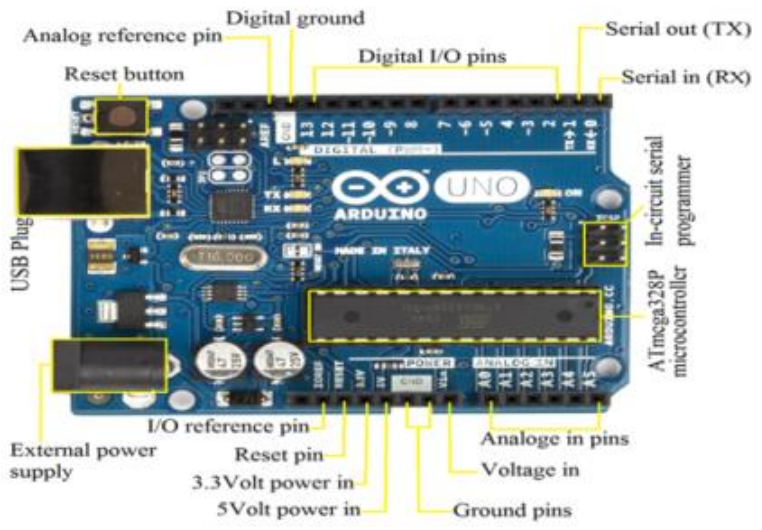

(a)

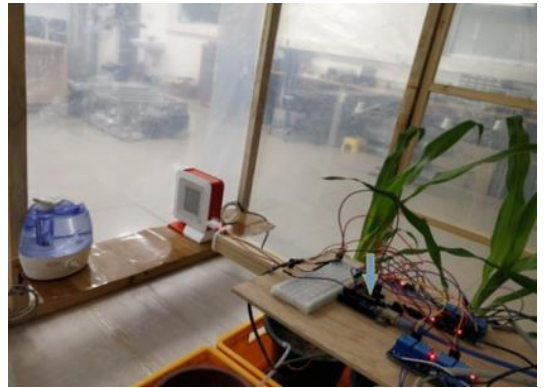

(b)

Figure 5. Arduino Uno

To make it started, it is need to connect to a computer through a USB cable or power it by using AC-to-DC adapter or battery. In this study we used Arduino software (IDE) 1.8.8.

Figure $5 \mathrm{~b}$ shows the device working during experiment.

Electrical relay. A relay is an electrical operated switch as sown in Figure 6a, the main use is controlling circuits or several circuits by a low-power signal, the Arduino relay module designed for different micro controllers such as the Arduino board, ARM, PIC, AVR, with digital outputs, this module incorporates 2 relays. Also, there are low - level and high level trigger expansion board.

A relay system contains input section and output section, input section involve $\mathrm{Vcc}$ (connected to the $5 \mathrm{~V}$ source on Arduino board), GND, (connected to the ground on Arduino board), In $1 \&$ In 2 (connected to digital output pins on Arduino board).

Output section of relay system involve series switches, 2 normally open (NO), 2 normally closed (NC), 2 common Pins (COM).

Figure $6 \mathrm{~b}$ illustrate the working of electrical relay during the experiment.
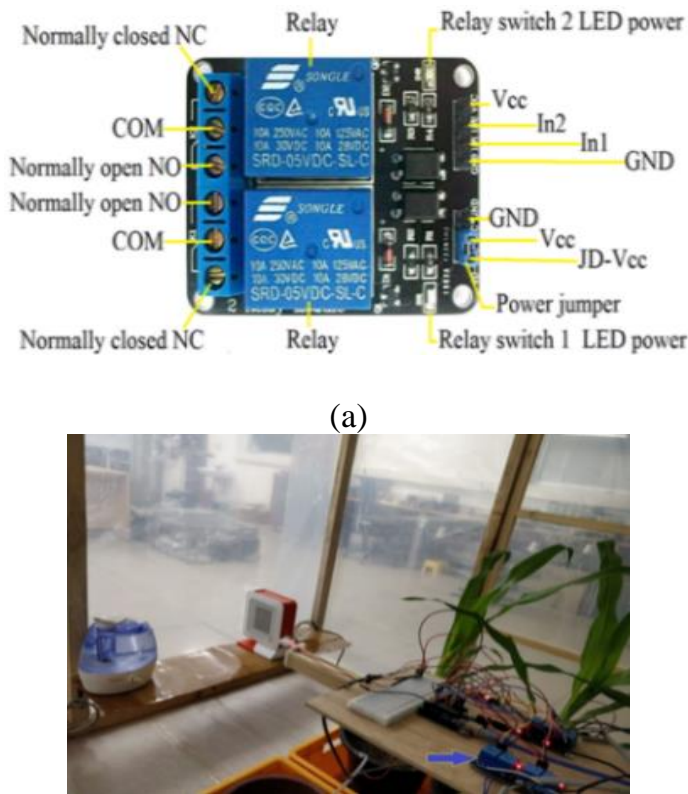

(b)

Figure 6. (2) Channels relay

Electrical fan. An electric DC fan fixed with prototype of greenhouse as illustrated in Figure 7 to make a ventilation process for air that required for plants, it is connecting with a relay to controlling the ON/OFF process according to $\mathrm{MC}$ program, the fan type MGA12012HR-A25 series G. 


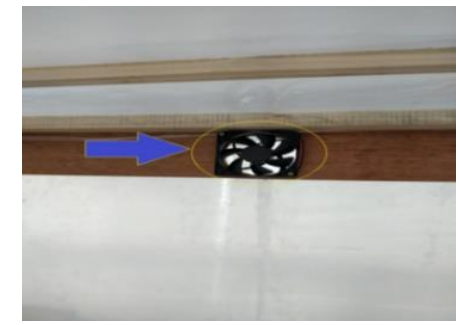

Figure 7. Electrical fan

Electric heater. A convection ceramic heater with a fan use to add heat to air and increase the temperature (Figure 8), the rated voltage AC 220-volt, rated power 1400 watt; the $\mathrm{ON} / \mathrm{OFF}$ process is controlling by relay according to $\mathrm{MC}$ program.

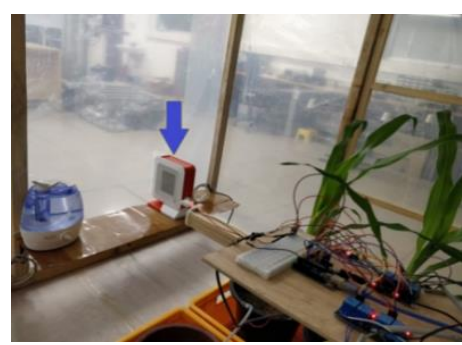

Figure 8. Electrical heater

Humidifier. An electric device type ultrasonic, model name DP-2050UH as marked in Figure 9, rated voltage AC 220-volt, frequency $60 \mathrm{~Hz}$, power consumption 35 watt, it is use to increase the relative humidity of air through evaporate the liquid water to water vapor. In this study, a relay and MC are used to controlling the ON/OFF process of humidifier.

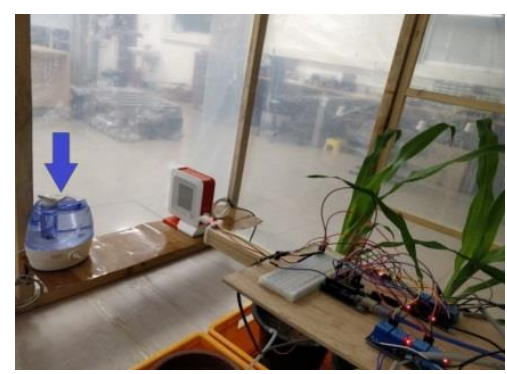

Figure 9. Humidifier

Submersible water pump. Two of DC submersible water pumps model type ultra-quiet mini, as marked in Figure 10, operating voltage dc $2.5-6 \mathrm{v}$, flow rate $80-120 \mathrm{~L} / \mathrm{h}$, maximum lift $40-110 \mathrm{~cm}$; are used to pumping water to soil according to MC signal to relay.

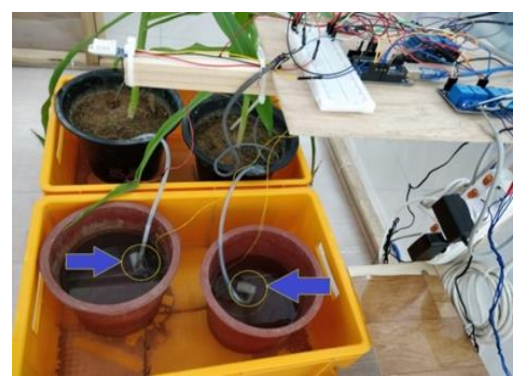

Figure 10. Submersible water pumps
Dehumidifier. An electric device with Peltier technology, works without compressor, the model name of device is hysure, Figure 11 illustrates the device in experiment, operating voltage dc 9 volt, power 23 watt; it has light weight, consumed low energy and use to decreasing the air $\mathrm{RH}$ through converting the water vapor in air from gas phase to liquid phase (water). The ON/OFF process controlled through relay which operate according to signal from Arduino MC.

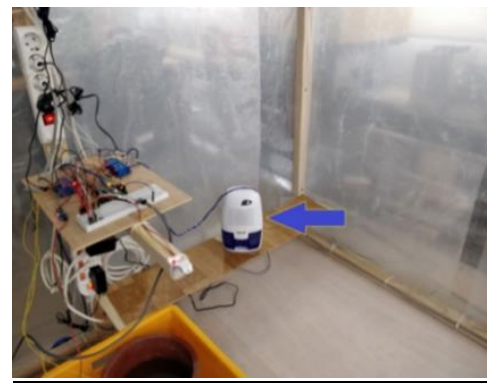

Figure 11. Dehumidifier

Others. Materials are use in experiment study involve switches, wires, AC to DC adapters to supplying devices with electric power, jumper wires are used to connect the sensors and relays with Arduino uno, also a USB cable and Laptop are use in process of monitoring and saving data.

\subsection{Experiment software}

After downloading Arduino software (IDE1.8.8) in computer from official web site of Arduino and open it a new sketch appear. It is need to choose Arduino/Genuine Uno and appropriate port from board under tools list in the program window are need before start writing program.

The program writing start with include DHT library and declare, defining DHT22 pin and other sensors, relays pins according to position labels on MC platform. Also define the on/off time for fan and using arduino program function (boolean) to repeat (on/off) action of fan continuously according to time setting.

In (void set up) function we specify the baud rate (9600) bits per second which is one of defaults for Arduino software and identifying sensors pins as input and relays pins as output through using (pinMode) function. A (Serial.println) function use to label and transfer the variables (Time hh:mm:ss, Date $\mathrm{mm} / \mathrm{dd} / \mathrm{yy}, \mathrm{R} . \mathrm{H} \%$, temp. ${ }^{\circ} \mathrm{C}$, Temp. ${ }^{\circ} \mathrm{F}$, soil moisture sensor value, Voltage of Soil moisture sensor, Leaf moisture sensor value, Voltage of Leaf moisture sensor) to Microsoft excel program by PLX-DAQ add-in software as a Data acquisition program.

In (void loop) we use (float) function to read air temperature in centigrade and Fahrenheit and the relative humidity, the use of (if else) function is to set the conditions of air temperature and relative humidity. Function (if-else-if) is use to controlling the submersible water pump operation according to output voltages of soil and leaf moisture sensors.

A serial print function use to indicate the measured data on Arduino serial monitor or on Microsoft excel program, at the end we use (delay) function to set time between each two measurement which is 2 second $(2000 \mathrm{~ms})$ in this study.

After complete program coding its need to use verify button in upper toolbar to check if there are errors in program coding, if there are not errors then the program upload to Arduino platform to start the controlling process. 


\subsection{Experiment study}

The experiment has conduct in smart logistics technology institute's laboratory, Sandan building, 4th floor, Hankyong national university, Anseongsi city, Gyungido province, South Korea, the laboratory which locate in $37^{\circ} 00^{\prime} 46.4^{\prime \prime} \mathrm{N}$ latitude, $127^{\circ} 15^{\prime} 37.5^{\prime \prime}$ E longitude.

The greenhouse prototype contains two pots with plant (maize transplanted in each), electrical heater, humidifier, dehumidifier and submersible water pumps, fan is fix on the side facing the door of prototype.

Arduino microcontroller use to control and monitoring Air temperature and relative humidity inside prototype according to set values in Arduino uploaded program (sketch).

The set value for air temperature is $27^{\circ} \mathrm{C}$ and for air relative humidity is 82 , signals are sent from Arduino MC to relays which are switch on/off the heater, humidifier, dehumidifier according to data sent from DHT22 sensor until reaching the desired conditions.

Also, Arduino Uno MC control air ventilation through define the time of fan switch on in 3 seconds and time of fan switch off in 26 seconds in Arduino control program and sending the signal to the relay to switch on or switch off accordingly.

In order to getting readings of output voltage of leaf and soil moistures sensors, and after controlling air temperature and relative humidity as mentioned above. A full irrigation is applied to the soil in the two pots by adding water to soil until water ooze from pots. The date of applying this process on 3009-2019 at 9 AM.

After 24 hours from full irrigating, the first readings of air temperature and relative humidity has collected from 9:00 AM to 2:30 PM, a data average has been calculating for every (5) minutes.

Also, output voltage of soil and leaf moisture sensors has been collected at the same period and average voltage has been calculating for every (5) minutes, and consider as readings at field capacity level of soil moisture. From these voltage readings, a specify average value of output voltage readings of leaf and soil sensors is use as reference at which submersible water pumps stop.

The process for collecting readings is repeating for next three days from 9:00 AM to 2:30 PM.

At plants wilted status, The readings have been collected also for one hour and average voltage has been calculating for every (5) minutes to measure the output voltages of soil and leaf moisture sensors, a specify average value use as a reference at which submersible water pumps switch on for irrigation.

The operation of submersible water pumps depends on data sent from YL-69 sensor which attached to one of the two pots at distance $10 \mathrm{~cm}$ below soil surface [21], and depend on AH$300 \mathrm{u}$ sensor which fixed to leaf of plant transplanted in other pot.

Figure 14 illustrates the control block diagram of experiment system; in addition, the diagram clarifies the delay that happen in during process action like heating or humidifying the air until the specified values reached, also it indicates the disturbance of sensor indicate in diagram which affect on the time of sensing.

Figures 13 and 15 illustrate the control algorithm for air temperature and humidity with both soil moisture and leaf moisture respectively and explain the processes paths according to their specified values.

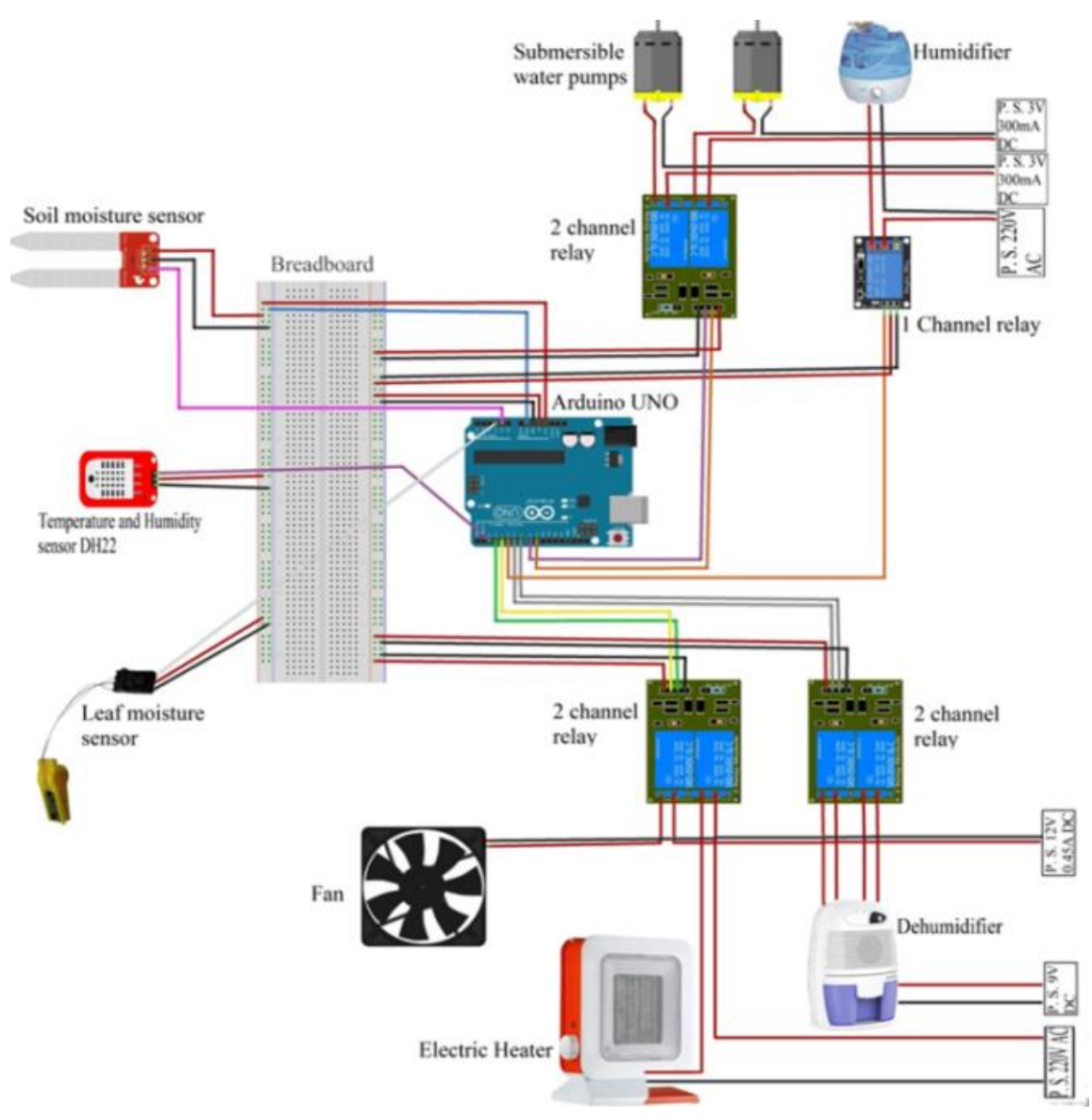

Figure 12. Experiment wiring circuit 


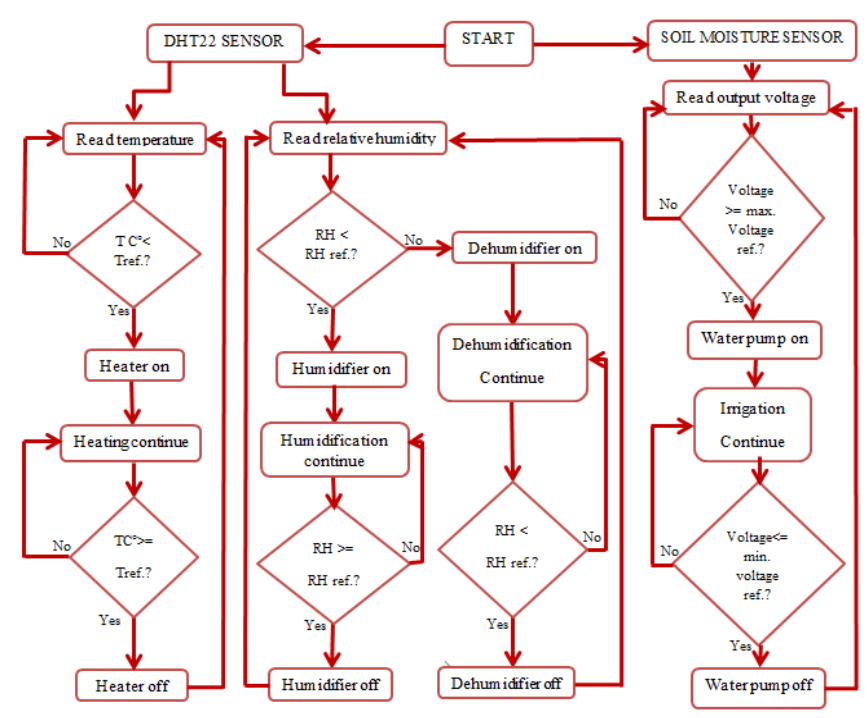

Figure 13. Control algorithm for air temperature and humidity with soil moisture

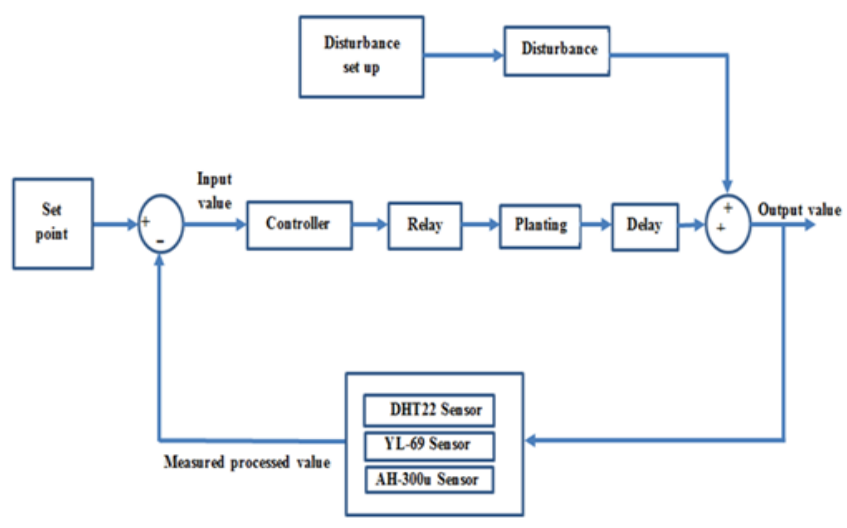

Figure 14. Control block diagram

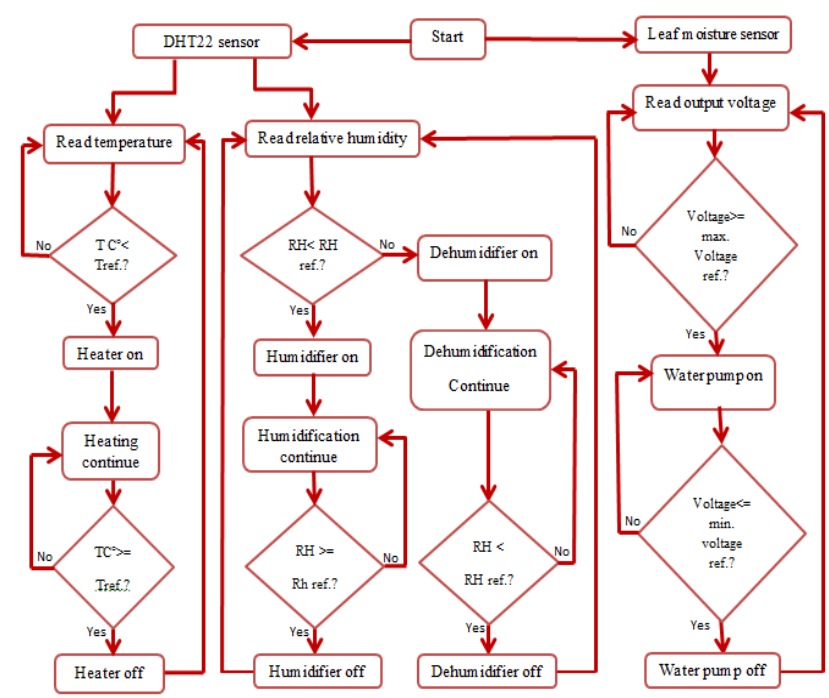

Figure 15. Control algorithm for air temperature and humidity with leaf moisture

\subsubsection{Experiment circuit}

The circuit consist of Arduino Uno MC powered by a $9 \mathrm{~V}$ 1A DC power supply adapter, a fan powered by a $12 \mathrm{~V} 0.5 \mathrm{~A}$ DC power supply adapter also dehumidifier powered by $9 \mathrm{~V}$
23 W DC power supply adapter, water submersible pumps powered by $3 \mathrm{~V} 300 \mathrm{~A}$ DC power supply adapter, heater and humidifier were powered by $220 \mathrm{~V}$ AC power supply, the electric DC positive charge wire passed through relay from normally open ports as well as AC negative charge wire to turn on/off the electrical devices.

The sensors are connecting to $3.3 \mathrm{~V} \mathrm{DC}$ power in Arduino Uno MC Platform. While the analog output data port of YL69 and $\mathrm{AH}-300 \mathrm{u}$ sensors are connect to analog pins (A1) and (A2) respectively.

The output digital data port of DHT22 sensor connects to digital pin (2) in Arduino Uno MC Platform while the relays connect to digital pins as illustrate in Figure 12. Jumper wires have use in these connections.

All pins related to circuit defined according to computer program which already uploaded to Arduino Uno MC.

All sensors and relays ground pins are connected to ground pin in Arduino Uno MC Platform. The data were monitored and saved through connect the computer (laptop) to Arduino Uno MC by USB cable.

3.4.2 Selection of air temperature, relative humidity and air moisture value

The critical temperature detrimentally affecting maize yield is approximately $32^{\circ} \mathrm{C}[22]$; the temperature chosen in experiment is $27^{\circ} \mathrm{C}$ which is near to optimal temperature [23].

In order to calculate relative humidity (R.H) of air we use Arrhenius equation:

$$
V_{\text {psat }}=e^{\left(\frac{A}{T}+B+C T+D T^{2}+E T^{3}+F \ln T\right)}
$$

where,

$\mathrm{V}_{\text {psat }}$ Saturation vapor pressure in (psi),

$A, B, C, D, E, F$ Constant values,

$A=-1.044 \times 10^{4}$,

$B=-11.29$,

$C=-2.7 \times 10^{-2}$,

$\mathrm{D}=1.289 \times 10^{-5}$,

$\mathrm{E}=-2.478 \times 10^{-9}$,

$\mathrm{F}=6.453$,

$\mathrm{T}$ is temperature in $\operatorname{Rankin}\left({ }^{\circ} \mathrm{R}\right)$.

$$
\begin{gathered}
T\left({ }^{\circ} \mathrm{R}\right)=T\left({ }^{\circ} \mathrm{F}\right)+459.67 \\
T\left({ }^{\circ} \mathrm{F}\right)=\left(\frac{9}{5} \times T\left({ }^{\circ} \mathrm{C}\right)\right)+32
\end{gathered}
$$

By applying $\mathrm{T}\left({ }^{\circ} \mathrm{C}\right)=27$ we calculate $\mathrm{V}_{\text {psat }}=0.52 \mathrm{psi}$,

$$
V P D=V_{\text {psat }} \times\left(1-\frac{R H}{100}\right)
$$

We consider optimal vapor pressure deficit VPD for greenhouse cultivation equal 0.65 according to Hatfield and Prueger [24], then:

$$
\begin{gathered}
0.65 K p a=\left(\frac{0.52}{0.145}\right) K p a \times\left(1-\frac{R H}{100}\right) \\
\mathrm{RH}=81.87 \approx 82
\end{gathered}
$$

The air moisture for each measured temperature $\left(\mathrm{F}^{\circ}\right)$ and R.H can be calculated from the equation below: 


$$
\begin{aligned}
& \text { Air moisture }\left(\frac{\text { grain }}{\mathrm{lb}}\right) \\
& \quad=\left(0.09065 \times \frac{\mathrm{RH}}{100} \times \mathrm{e}^{\frac{\mathrm{T}\left({ }^{\circ} \mathrm{F}\right)}{28.116}}\right)
\end{aligned}
$$

1 grain $=0.06480$ gram, $1 \mathrm{lb}=0.4536 \mathrm{~kg}$.

$$
\mathrm{V}_{\text {pair }}=\mathrm{V}_{\text {psat }} \times\left(\frac{\mathrm{RH}}{100}\right)
$$

where, $\mathrm{V}_{\text {pair }}$ is a vapor pressure of air in Kpa.

\subsubsection{Fan settings}

The range of air exchange for plants is 4-10 (minutes) [25], the size of prototype is $6 \mathrm{~m}^{3}$, we set the air exchange 5 minute so:

$$
\begin{gathered}
\frac{f t^{3}}{\text { minute }} \text { of fan }=\frac{\text { Prototype Volume }}{\text { Air exchange per minute }}= \\
\frac{\left(6 \mathrm{~m}^{3} \times 35.315 \frac{\mathrm{ft}^{3}}{\mathrm{~m}^{3}}\right)}{5 \text { minutes }}=42.4
\end{gathered}
$$

The available fan in experiment type MGA12012HR-A25 series G with $84.8 \frac{f^{3}}{\text { minute }}$ [26], in the program codes (sketch) which upload to Arduino Uno MC. The fan operation has set switch on for 3 seconds and switch off for 26 seconds to obtain $\frac{f t^{3}}{\text { minute }}$ value near to 42.4 for every 5 minutes instead of getting $84.8 \mathrm{ft}^{3}$ in one minute.

$$
\begin{aligned}
84.8 \frac{f t^{3}}{\text { minute }}=1.42 \frac{f t^{3}}{\text { second }} \\
1.42 \frac{f t^{3}}{\text { second }} \times \text { Time on (second) } \\
\times \text { Number of duplicates per minute } \\
\times \text { Air exchange (minute) } \\
=1.42\left(\frac{f t^{3}}{\text { second }}\right) \times 3(\text { Second }) \times 2 \\
\times 5 \text { (Minute) }=42.6 \mathrm{ft}^{3} \text { for } 5 \text { minutes }
\end{aligned}
$$

\subsubsection{Water submersible pump setting}

Because the water flow rate depends on electrical voltage and current supply, it is necessary to making a calibration for water submersible pump at experiment conditions, height $\mathrm{H}=$ $(23.5 \mathrm{~cm})$ from pump outlet to upper surface of pot, voltage DC (3 volt), DC current (300 mA).

We found that, the pump needs 13 second to discharge 0.2 $\mathrm{L}$, so the flow rate will be:

$$
\mathrm{Q}=0.2 \mathrm{~L} / 13 \mathrm{sec}=0.0154 \mathrm{~L} / \mathrm{sec} .=55.44 \mathrm{~L} / \mathrm{h}
$$

Table 2. Decision table for controlling flow rate valve according to air temperature and SMSV

\begin{tabular}{ccccc}
\hline Soil Moisture Sensor & \multicolumn{5}{c}{ Temperature $\left({ }^{\circ} \mathbf{C}\right)$} \\
\cline { 2 - 5 } Voltage SMSV $(\mathbf{v})$ & $\mathbf{2 5}$ & $\mathbf{2 7}$ & $\mathbf{2 9}$ & $\mathbf{3 1}$ \\
\hline SMSV $\leq \mathbf{0 . 8 2 6} \mathbf{v}$ & CL & CL & CL & CL \\
\hline $\mathbf{0 . 8 2 6}$ v $<$ SMSV $\leq \mathbf{0 . 9 9 4}$ v & HCL & HCL & HCL & HCL \\
\hline $\mathbf{0 . 9 9 4} \mathbf{v}<$ SMSV $\leq \mathbf{1 . 1 6 2}$ v & N & N & N & N \\
\hline $\mathbf{1 . 1 6 2}$ v $<$ SMSV $\leq \mathbf{1 . 3 2 9}$ v & HO & HO & HO & HO \\
\hline SMSV $\geq \mathbf{1 . 3 2 9}$ v & O & O & O & O \\
\hline
\end{tabular}

Table 3. Decision table for controlling flow rate valve according to air relative humidity\% and SMSV

\begin{tabular}{ccccc}
\hline Soil Moisture Sensor Voltage & \multicolumn{5}{c}{ Relative Humidity (RH \%) } \\
\cline { 2 - 5 } SMSV $(\mathbf{v})$ & 81 & 82 & 83 & 84 \\
\hline SMSV $\leq \mathbf{0 . 8 2 6} \mathbf{v}$ & CL & CL & CL & CL \\
\hline $\mathbf{0 . 8 2 6} \mathbf{v}<\mathbf{S M S V} \leq \mathbf{0 . 9 9 4 v}$ & HCL & HCL & HCL & HCL \\
\hline $\mathbf{0 . 9 9 4} \mathbf{v}<\mathbf{S M S V} \leq \mathbf{1 . 1 6 2} \mathbf{v}$ & N & N & N & N \\
\hline $\mathbf{1 . 1 6 2} \mathbf{v}<\mathbf{S M S V} \leq \mathbf{1 . 3 2 9} v$ & HO & HO & HO & HO \\
\hline SMSV $\geq \mathbf{1 . 3 2 9}$ v & O & O & O & O \\
\hline CL closed, HCL high closed, N normal, HO high open, O open
\end{tabular}

Table 4. Decision table for controlling flow rate valve according to air temperature and LMSV

\begin{tabular}{ccccc}
\hline Leaf Moisture Sensor Voltage & \multicolumn{4}{c}{ Temperature $\left({ }^{\circ} \mathbf{C}\right)$} \\
\cline { 2 - 5 } LMSV $(\mathbf{v})$ & $\mathbf{2 5}$ & $\mathbf{2 7}$ & $\mathbf{2 9}$ & $\mathbf{3 1}$ \\
\hline LMSV $\leq \mathbf{1 . 3 9 2} \mathbf{v}$ & CL & CL & CL & CL \\
\hline $\mathbf{1 . 3 9 2} \mathbf{v}<\mathbf{L M S V} \leq \mathbf{1 . 4} \mathbf{v}$ & HCL & HCL & HCL & HCL \\
\hline $\mathbf{1 . 4} \mathbf{v}<\mathbf{L M S V} \leq \mathbf{1 . 4 0 8} \mathbf{v}$ & N & N & N & N \\
\hline $\mathbf{1 . 4 0 8} \mathbf{v}<\mathbf{L M S V} \leq \mathbf{1 . 4 1 6} \mathbf{v}$ & HO & HO & HO & HO \\
\hline LMSV $\geq \mathbf{1 . 4 2 4} \mathbf{v}$ & O & O & O & O \\
\hline CL closed, HCL high closed, N normal, HO high open, O open
\end{tabular}

Table 5. Decision table for controlling flow rate valve according to air relative humidity\% and LMSV

\begin{tabular}{ccccc}
\hline $\begin{array}{c}\text { Leaf Moisture Sensor } \\
\text { Voltage LMSV }(\mathbf{v})\end{array}$ & \multicolumn{4}{c}{ Relative Humidity (RH \%) } \\
\cline { 2 - 5 } $\mathbf{8 1}$ & $\mathbf{8 2}$ & $\mathbf{8 3}$ & $\mathbf{8 4}$ \\
\hline $\mathbf{L M S V} \leq \mathbf{1 . 3 9 2} \mathbf{v}$ & CL & CL & CL & CL \\
\hline $\mathbf{1 . 3 9 2} \mathbf{v}<\mathbf{L M S V} \leq \mathbf{1 . 4} \mathbf{v}$ & HCL & HCL & HCL & HCL \\
\hline $\mathbf{1 . 4} \mathbf{v}<$ LMSV $\leq \mathbf{1 . 4 0 8} \mathbf{v}$ & N & N & N & N \\
\hline $\mathbf{1 . 4 0 8} \mathbf{v}<$ LMSV $\leq \mathbf{1 . 4 1 6} \mathbf{v}$ & HO & HO & HO & HO \\
\hline LMSV $\geq \mathbf{1 . 4 2 4} \mathbf{v}$ & O & O & O & O \\
\hline CL closed, HCL high closed, N normal, HO high open, O open
\end{tabular}

In Tables 1-5 above, the (HCL) denoted to the opining status of flow rate valve (near to close) which is between the closed status CL and normal N status; as well as (HO) denoted to the opining status of flow rate valve (near to open) which is between the open status $\mathrm{O}$ and normal $\mathrm{N}$ status.

\section{EXPERIMENTAL RESULTS AND DISCUSSION}

The study found from the experimental data collected from inside prototype by using data acquisition program (PLXDAQ), that the average air temperature on day (1-10-2019) is $27^{\circ} \mathrm{C}$ for the period from ( $9 \mathrm{AM}-2: 30 \mathrm{PM}$ ) and the average relative humidity (\%) is 82.7 (see Figure 16).

The average voltages of leaf and soil moistures for the same day and time sampling are $1.392 \mathrm{v}$ and $0.826 \mathrm{v}$ respectively (see Figure 17). While the average air moisture and VPD are 18.78-gram water/Kg dry air and 0.62 as illustrate in Figure 18.

On the second day (2-10-2019) of experiment, the average of air temperature is $27^{\circ} \mathrm{C}$ and average relative humidity (\%) is 82.6 as illustrate in Figure 19.

In Figure 20, the average voltages of leaf and soil moisture sensors are $1.398 \mathrm{v}$ and $0.988 \mathrm{v}$ respectively. While the average of air moisture and VPD are $18.85 \mathrm{gr}$ water/Kg dry air and 0.62 as illustrate in Figure 21.

On the day (3-10-2019), the average air temperature is $27^{\circ} \mathrm{C}$ and the relative humidity (\%) is 82.6 (see Figure 22). 


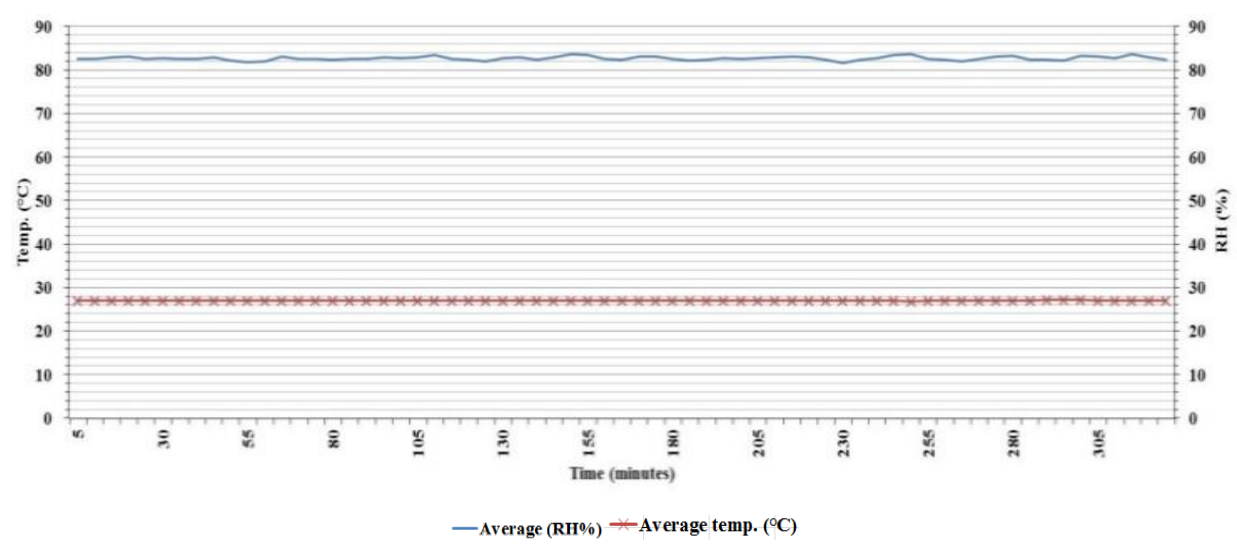

Figure 16. Air R.H, temperature (1-10-2019)

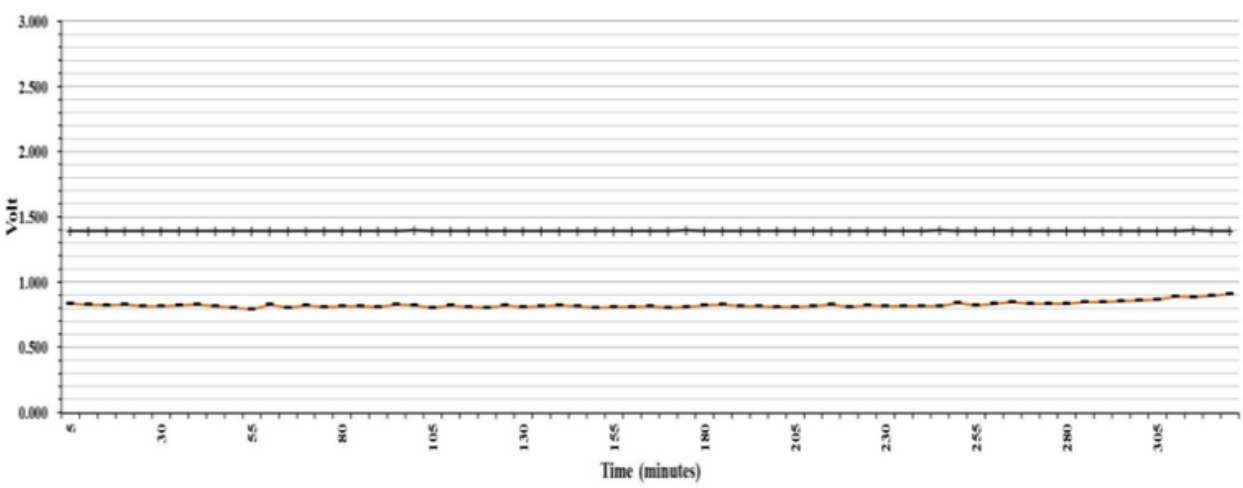

-Average Voltage of leaf moisture sen sor (volt) - - Average voltage of soil moisture sen sor (volt)

Figure 17. Voltages of soil and leaf sensors (1-10-2019)

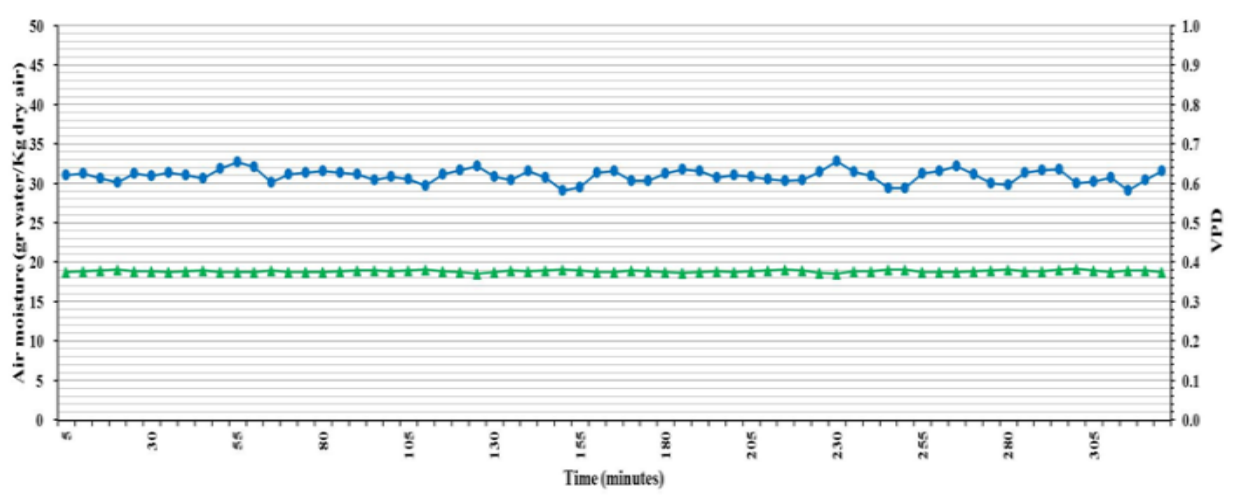

-Average of Vapor pressure defict (VPD) - Average of Air moisture ( $\mathrm{g}$ water $/ \mathrm{kg}$ dry air)

Figure 18. Air moisture and VPD (1-10-2019)

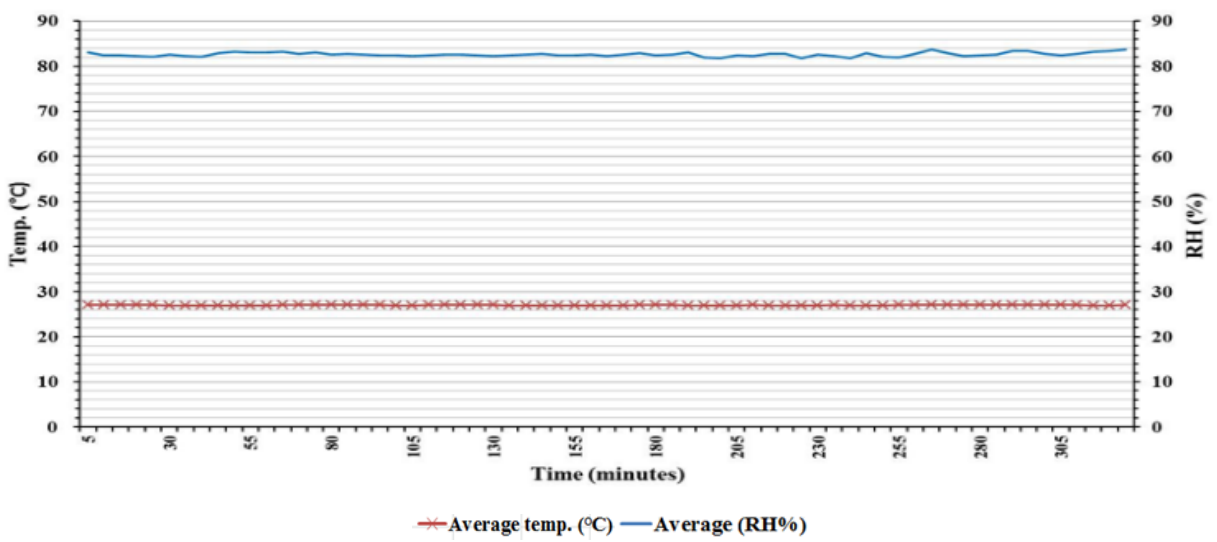

Figure 19. Air R.H, temperature (2-10-2019) 


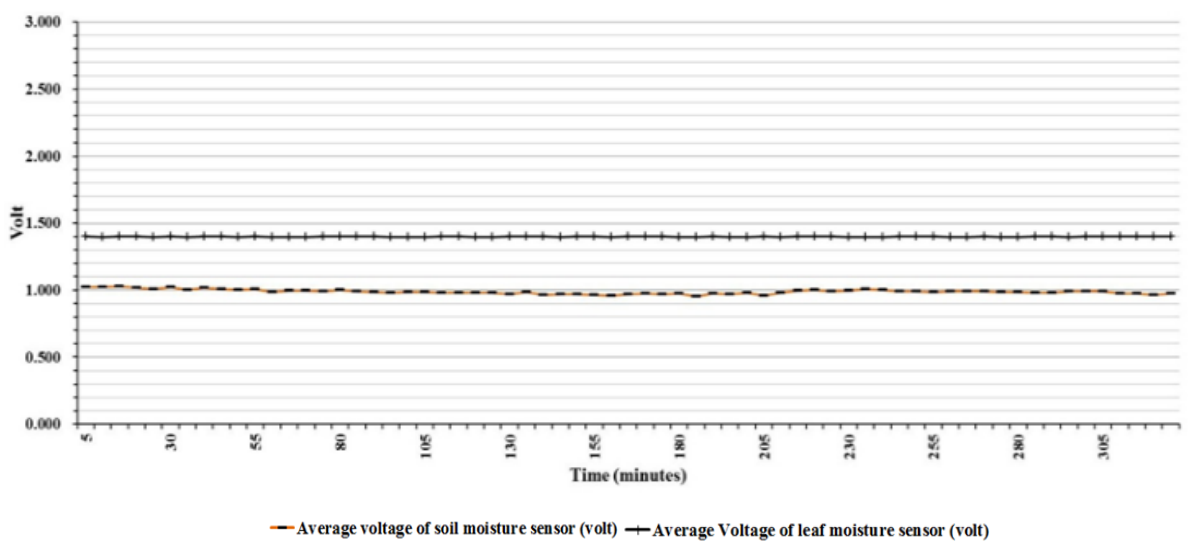

Figure 20. Voltages of soil and leaf sensors (2-10-2019)

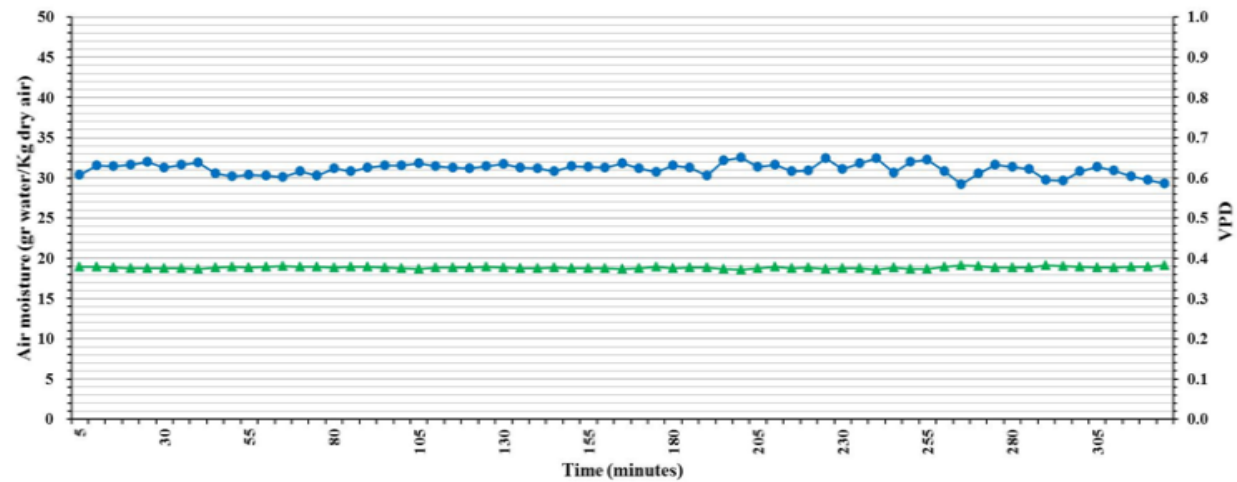

-Average of Air moisture ( $\mathrm{g}$ water $/ \mathrm{kg} \mathrm{dry}$ air) $\rightarrow$-Average of Vapor pressure deficit (VPD)

Figure 21. Air moisture and VPD (2-10-2019)

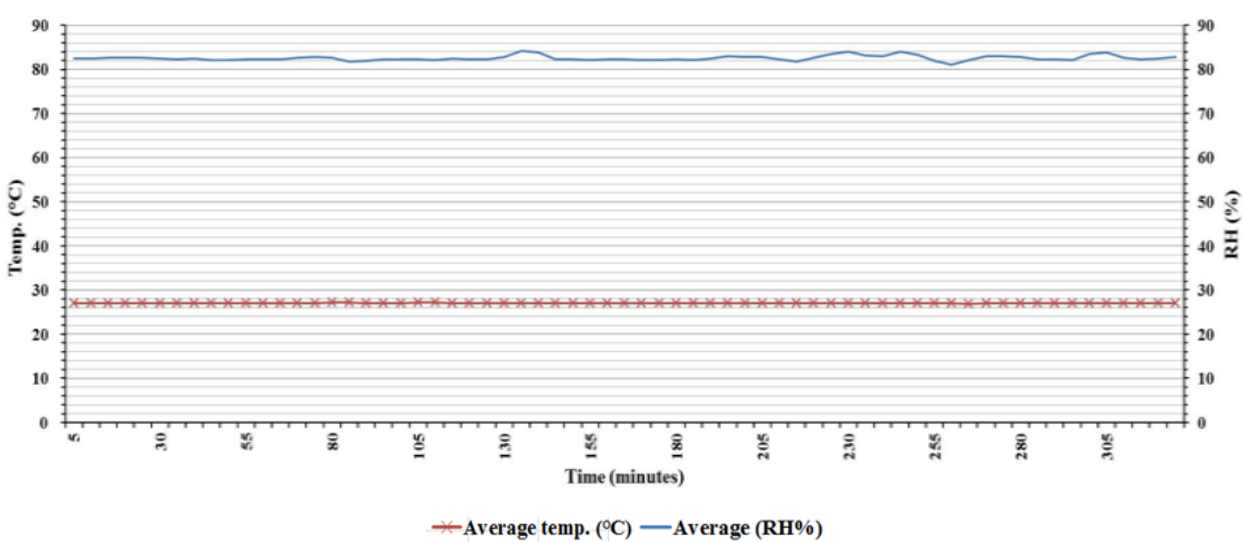

Figure 22. Air R.H, temperature (3-10-2019)

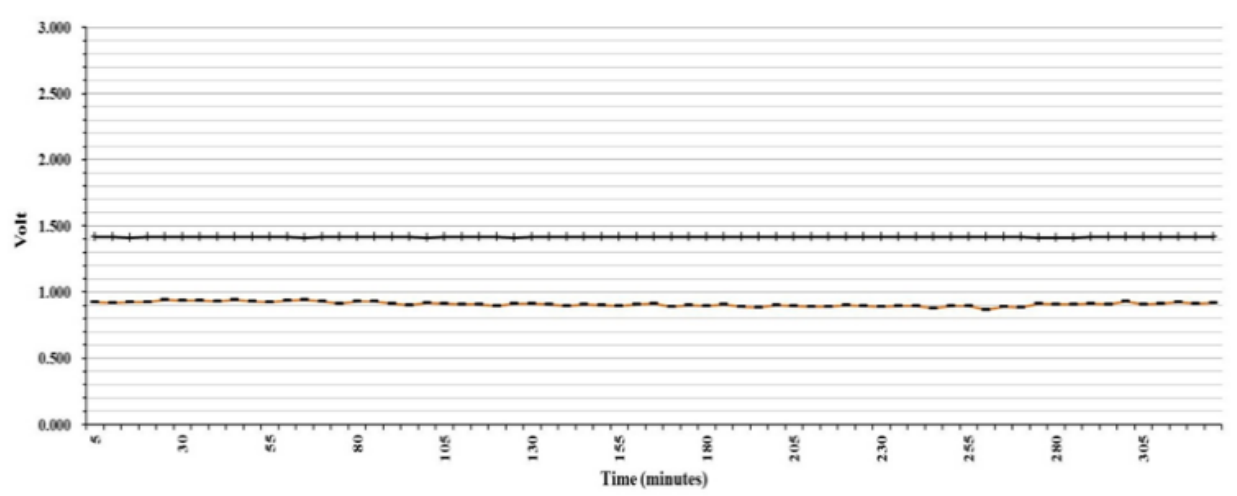

-Average voltage of soil moisture sen sor (volt) - Average Voltage of leaf moisture sen sor (volt)

Figure 23. Voltages of soil and leaf sensors (3-10-2019) 
The average voltages of leaf and soil moistures sensors are $1.416 \mathrm{v}$ and $0.909 \mathrm{v}$ respectively (see Figure 23). while the average of air moisture is $18.84 \mathrm{gr}$ water/Kg dry air and 0.62 for VPD as illustrate in Figure 24.

On the fourth day of experiment (4-10-2019), the average air temperature is $27^{\circ} \mathrm{C}$ and average relative humidity 82.4 as illustrate in Figure 25.

Figure 26 shows that the average voltages of leaf and soil moisture sensors are $1.416 \mathrm{v}$ and $0.810 \mathrm{v}$ respectively. While the average of air moisture is 20.03 gr water/Kg dry air and the VPD is 0.63 (Figure 27).

At a wilted plants status, the average air temperature is $27^{\circ} \mathrm{C}$ and the air relative humidity is 81.8 as illustrate in Figure 28 .

The average output voltage of leaf and soil moisture sensors are $1.424 \mathrm{v}$ and $1.329 \mathrm{v}$ respectively as see in Figure 29, while the average of air moisture is $18.64 \mathrm{gr}$ water/Kg dry air and VPD is 0.65 (see Figure 30).

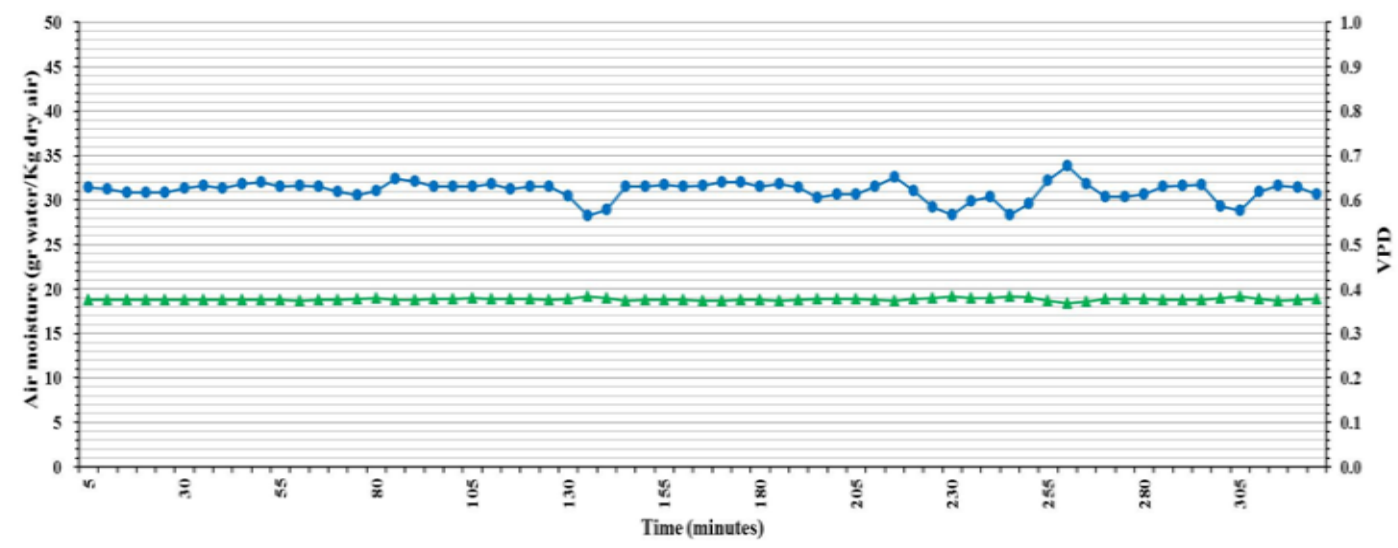

-Average of Air moisture ( $g$ water/kg dry air) $\rightarrow$ Average of Vapor pressure deficit (VPD)

Figure 24. Air moisture and VPD (3-10-2019)

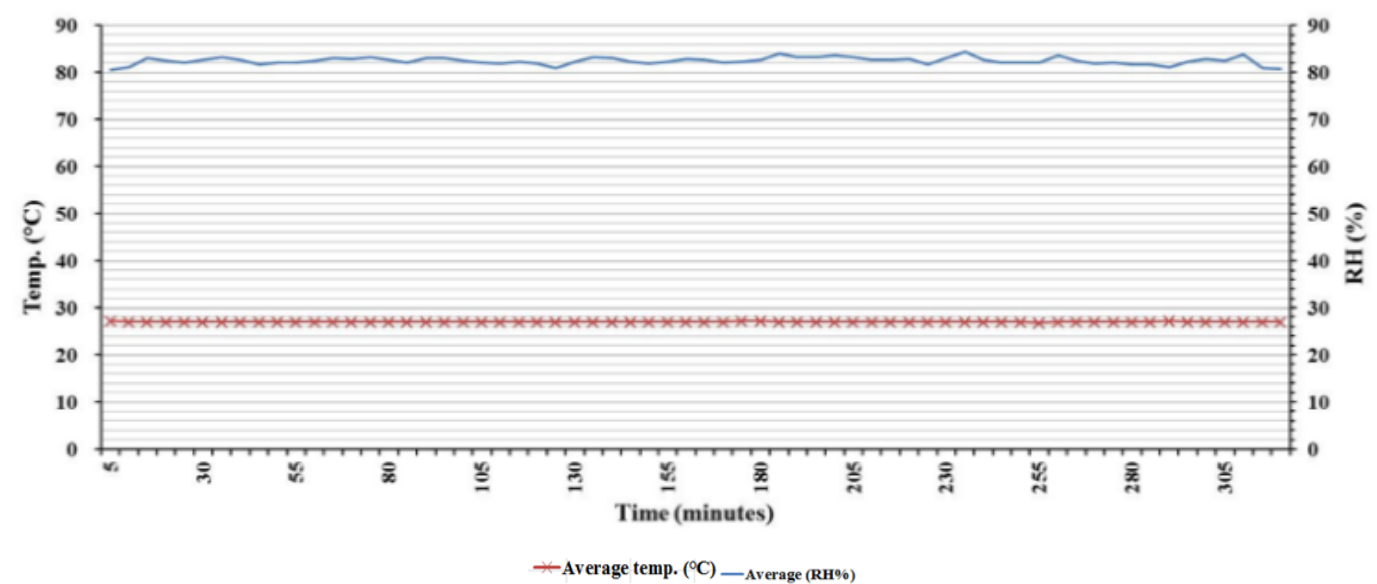

Figure 25. Air R.H, temperature (4-10-2019)

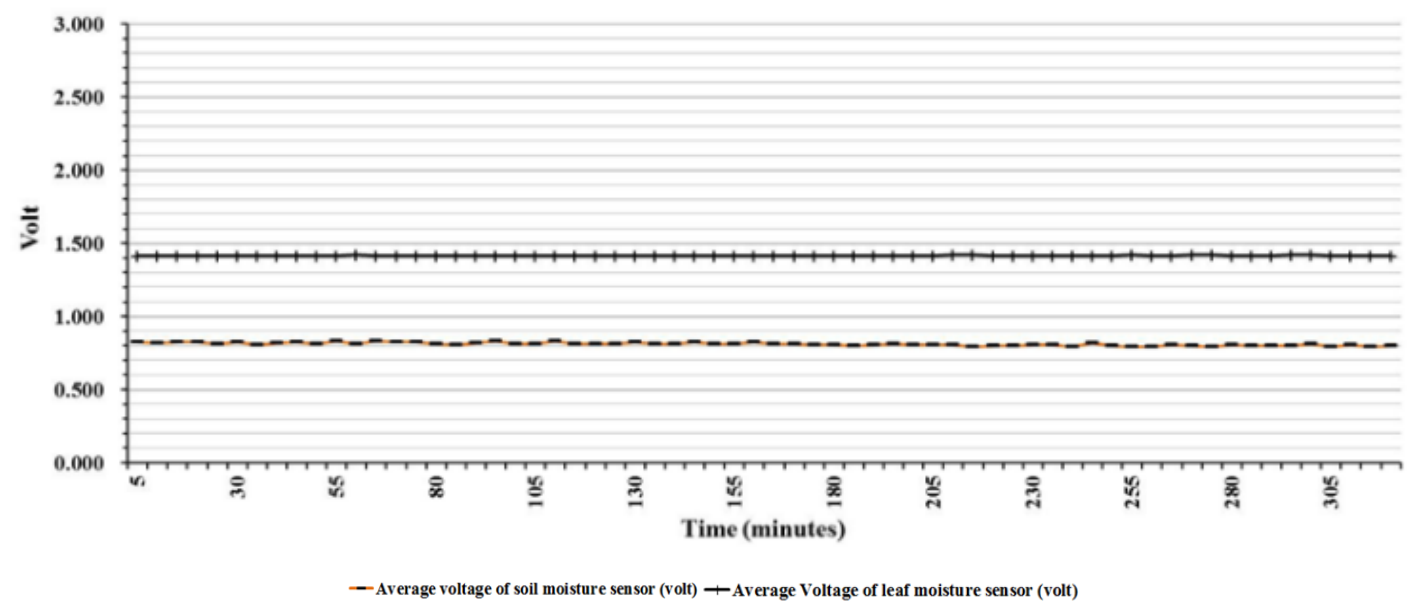

Figure 26. Voltages of soil and leaf sensors (4-10-2019) 


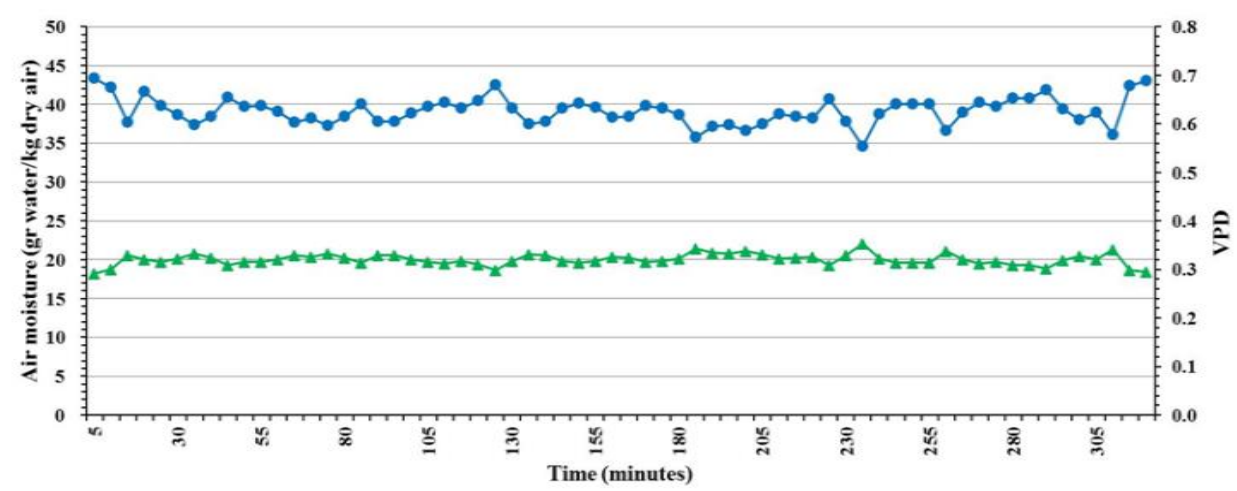

$\rightarrow$ Average of Vapor pressure deficit (VPD) - Average of Air moisture ( $\mathrm{g}$ water $/ \mathrm{kg}$ dry air)

Figure 27. Air moisture and VPD (4-10-2019)

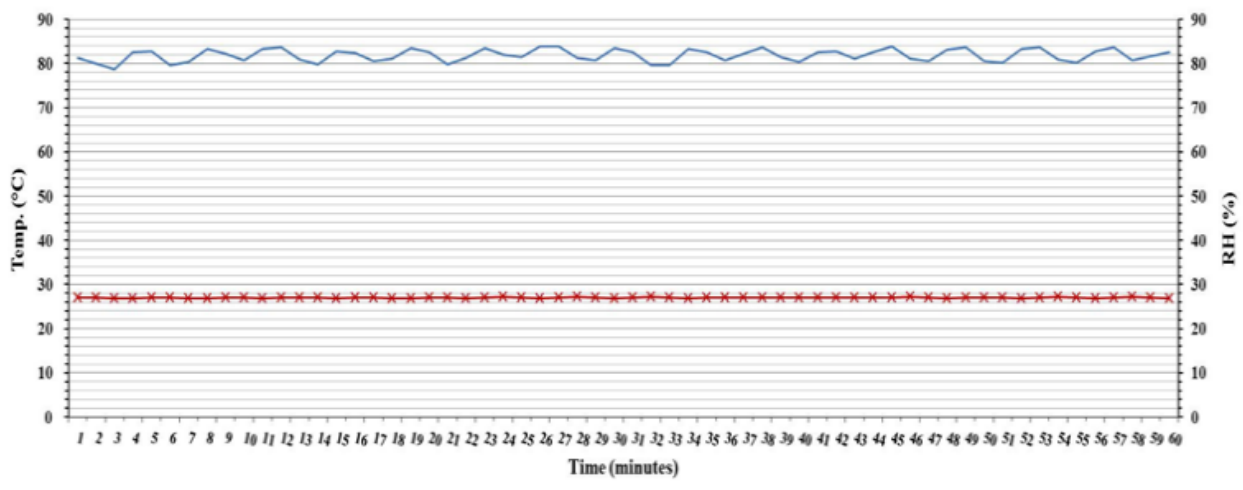

$\rightarrow$ Average temp. $\left({ }^{\circ} \mathrm{C}\right)$ - Average $(\mathrm{RH} \%)$

Figure 28. Air R.H, temperature when plants wilted (Sampling time 1 hour)

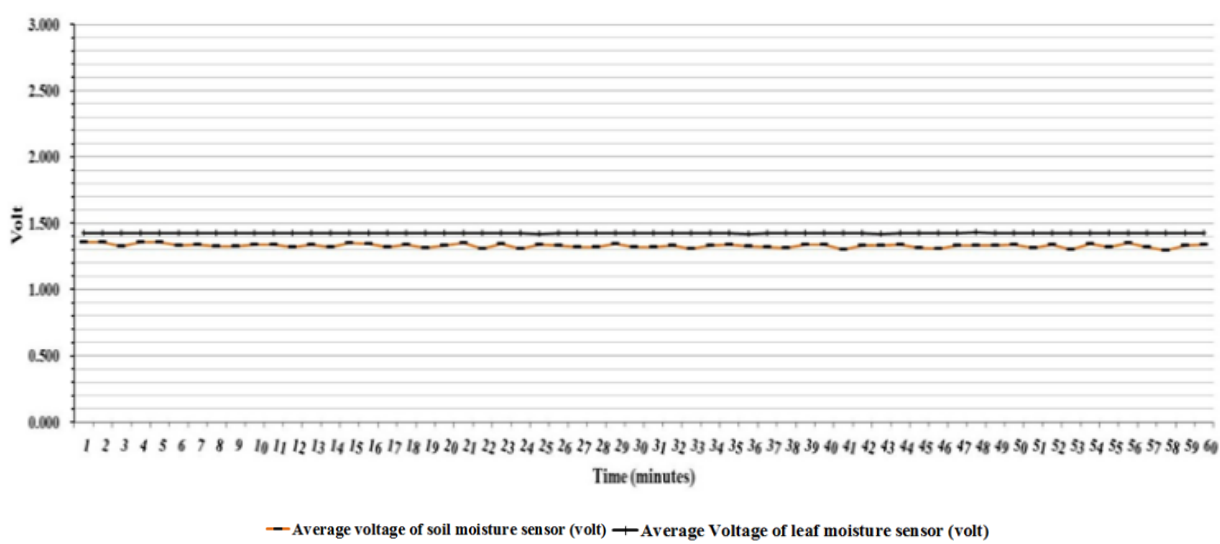

Figure 29. Voltages of soil and leaf sensors when plants wilted (Sampling time 1 hour)

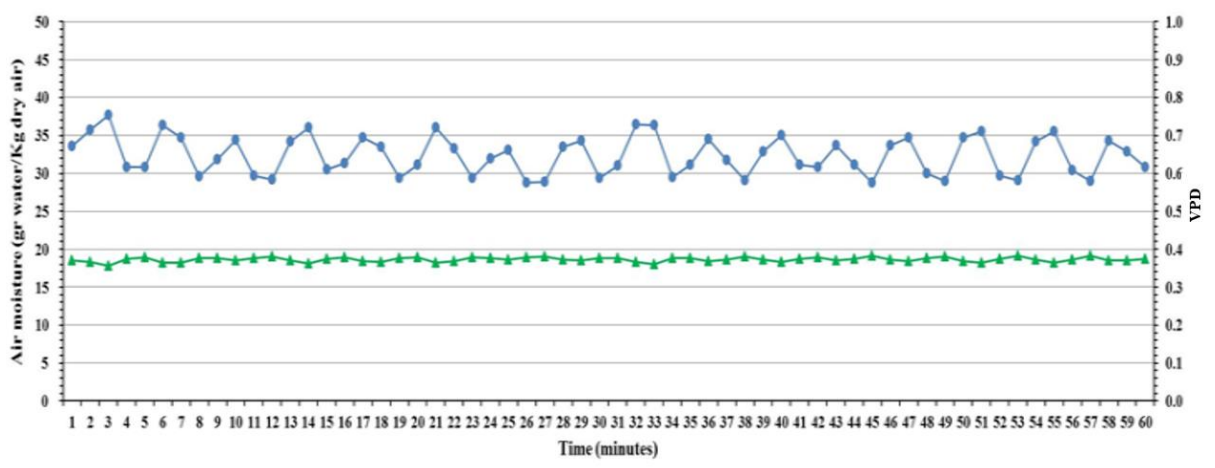

$\rightarrow$ Average of Vapor pressure deficit (VPD) $\rightarrow$ Average of Air moisture ( $\mathrm{g}$ water $/ \mathrm{kg}$ dry air)

Figure 30. Air moisture and VPD when plants wilted (Sampling time 1 hour) 
As a result from above, the air temperature maintains at $27^{\circ} \mathrm{C}$ during the four days of experiment, the relative humidity has (0.7) as a maximum increase from reference value (82) due to increasing of weather air humidity outside the prototype which affects on the dehumidifier efficiency.

The output voltages of soil moisture sensor were stable in range nearly $(0.8-1)$ volt on the four days of experiment mentioned above due to the effect of controlling environment at optimum.

Also the voltage of leaf moisture sensor AH-300u slightly increase from 1.392 volt after 24 hours of full irrigation to 1.424 volt at wilted condition of plant leaf which marks decreasing in moisture inside the maize leaf until it reached the wilting condition.

The output voltages of soil moisture sensor YL-69 increased from 0.826 volt after 24-hour of full irrigation to 1.329 volt when plant was wilted; these output voltages values of leaf and soil moistures sensors use as maximum and minimum levels to controlled irrigation operation.

\section{CONCLUSIONS AND RECOMMENDATIONS}

This study focused on controlling the air temperature and controlling humidity in form of RH. From the experimental results which obtain and according to the specifications of sensors, the air temperature has been control to a reference value $27{ }^{\circ} \mathrm{C}$ during the experiment period. The relative humidity $(\%)$ has been control to reference value 82 with slightly increasing of 0.7 due to high humidity in outer weather which influence on dehumidifier efficiency. The relative humidity of air inside the prototype shows an influence on air moisture content and VPD, so it's necessary to choose dehumidifier device with high range of working ( $\mathrm{RH}$ above $90 \%$ ).

This study proves the programming cycles to switch on/off the heater, humidifier, dehumidifier and air fan was performed successfully by using Arduino Uno MC and relays. Successfully maintain the air temperature and humidity for maize plants. Regarding the irrigation, the study conclude that it is much better to use soil moisture sensor to applying the amount of water needed for plant than using leaf moisture sensor because the leaf moisture needs more time to increasing than the time need to increase the moisture in soil.

A decision table has been suggest to controlling the irrigation water flow rate by using flow rate valve in which the flow opening can be switched to (CL closed, HCL high closed, $\mathrm{N}$ normal, $\mathrm{HO}$ high open, $\mathrm{O}$ open) according to different ranges of moistures sensors output voltage at different air temperatures and relative humidity instead of depending on one range, this method will minimized the irrigation water consumption with consider the effectiveness of using leaf moisture sensor to controlling irrigation.

In future studies, a design of temperature and humidity controller can be done according to differential controller by using multi sensors data in zone to get the overall air temperature and humidity. More studies can be done in controlling environment factors like light intensity, carbon dioxide concentration in air, nitrogen concentration in soil. A calibration of soil and leaf moisture with air factors can be study in which can be use in agricultural open fields.

Also making a combination data of air temperature, relative humidity, moistures of soil and leaf can be use in the open fields not only in greenhouses. As well as it can be used to predicting the best time of harvesting for some crops like maize or barley and wheat which need specified values of leaf and soil moistures in order to minimize pre or post harvesting losses.

Further studies can be deal with the difference of power supply consumption or controlling effect on different plants.

\section{ACKNOWLEDGEMENT}

I would like to express my thanks and appreciation to the supervisor Professor Yong-Tae Kim for the valuable support and important advices that he gave me during the research stages, also I would like to thank the university administration represented by the President of the University and all professors, especially mentioning Professor Seong-Jik Park, Professor Soo-Cheul Yoo, Professor Han-Joong Kim, Professor Seong-gu Hong, Emeritus Professor Nam-Ho Lee. Sincere gratitude to my fellow Korean students in smart logistics technology institute's laboratory. Deeply grateful to Korean International Cooperation Agency (KOICA) for giving me this opportunity to obtain a Master's Degree in Smart Agricultural Engineering and for the continuous support and follow-up through their office at the University. At the end I would like to dedicate this work to my deceased father and brothers, to my mother, and to my wife and my sons.

\section{REFERENCES}

[1] Von Zabeltitz, C. (2011). Integrated Greenhouse Systems for Mild Climates. Springer-Verlag Berlin Heidelberg. https://doi.org/10.1007/978-3-642-14582-7

[2] Pérez-Parra, J., Ramírez-Arias, A., Berenguel, M., Rodríguez, F. (2006). Ventilation rate models of Mediterranean greenhouses for control purposes. Acta Hortic, 719:

197-204. https://doi.org/10.17660/ActaHortic.2006.719.20

[3] DeGannes, A., Heru, K.R., Mohammed, A., Paul, C., Rowe, J., Sealy, L., Seepersad, G. (2014). Tropical Greenhouse Growers Manual for the Caribbean, CARDI, Trinidad.

[4] Jenson, M.H., Malter, A.J. (1995). Protected Agriculture - A Global Review. World Bank Technical Paper No. 253, Washington D.C., USA.

[5] Pieš, M., Hajovsky, R., Ozana, S. (2013). Autonomous monitoring system for measurement of parameters of heat collection technology at thermal active mining dumps. Elektronika it Elektrotechnika, 19(10): 62-65. https://doi.org/10.5755/j01.eee.19.10.5898

[6] Pieš, M., Hajovsky, R., Latocha, M., Ozana, S. (2014). Radio telemetry unit for online monitoring system at mining dumps. Applied Mechanics and Materials, 548549: $736-743$ https://doi.org/10.4028/www.scientific.net/AMM.548549.736

[7] Luo, H., Yang, P.L., Li, Y.K., Xu, F.P. (2012). An intelligent controlling system for greenhouse environment based on the architecture of the Internet of Things. Sensor Letters, 10(1-2): 514-522. https://doi.org/10.1166/s1.2012.1850

[8] Olvera-Olvera, C.A., Duarte-Correa, D., RamirezRodriguez, S.R., Alaniz-Lumbreras, P.D., Lara-Herrera, A., Gomez-Melendez, D., Aguilera-Soto, J.I., Araiza- 
Esquivel, M.A., Villa-Hernandez, J.J., GonzalezRamirez, E., Herrera-Ruiz, G. (2011). Development of a remote sensing and control system for greenhouse application. African Journal of Agricultural Research, 6(21): 4947-4953. https://doi.org/10.5897/AJAR11.1231

[9] Lee, K.O., Suh, B.Y., Bae, Y., Yang, J.Y., Jeong, Y.Y., Nakaji, K. (2011). Development of an integrated greenhouse monitoring and control system at province level. Journal of the Faculty of Agriculture Kyushu University, 56(2): 379-387.

[10] David, J., Jancikova, Z., Frischer, R., Vrozina, M. (2013). Crystallizer's desks surface diagnostics with usage of robotic system. Archives of Metallurgy and Materials, 58(3): 907-910. https://doi.org/10.2478/amm-2013-0098

[11] Abdullah, A., Barnawi, A. (2012). Identification of the type of agriculture suited for application of sensor wireless networks. Russ. J. Agric. Sosio-Economic Sci., 12(12): 19-36. https://doi.org/10.18551/rjoas.2012-12.02

[12] Chuah, H.T., Kam, S.W., Chye, Y.H. (1997). Microwave dielectric properties of rubber and oil palm leaf samples: Measurement and modeling. Int. J. Remote Sensing, 18(12): 2623-2639. https://doi.org/10.1080/014311697217503

[13] Ferrarezi, R.S., Van Iersel, M.W., Testezlaf, R. (2014). Subirrigation automated by capacitance sensors for salvia production. Horticultura Brasileira, 32(3): 314320. 05362014000300013

[14] Nemali, K.S., Montesano, F., Dove, S.K., Van Iersel, M.W. (2007). Calibration and performance of moisture sensors in soilless substrates: $\mathrm{ECH}_{2} \mathrm{O}$ and Theta probes. Sci. Hort., 112(2): 227-234. https://doi.org/10.1016/j.scienta.2006.12.013

[15] Jones, H.G. (2004). Irrigation scheduling: Advantages and pitfalls of plant-based methods. J. Expt. Bot., 55(407): 2427-2436. https://doi.org/10.1093/jxb/erh213

[16] Nemali, K.S., Van Iersel, M.W. (2006). An automated system for controlling drought stress and irrigation in potted plants. Sci. Hort., 110(3): 292-297. https://doi.org/10.1016/j.scienta.2006.07.009

[17] Shock, C.C., Wang, F.X. (2011). Soil water tension, a powerful measurement for productivity and stewardship.
Hort-Science, 46(2): https://doi.org/10.21273/HORTSCI.46.2.178

178-185.

[18] Suraj, M., Ekwue, E.I., Birch, R.A., Augustine, T., Indies, W. (2018). A controlled environment agriculture greenhouse for the Caribbean Region. The West Indian Journal of Engineering, 40(2): 10-16.

[19] Afzal, A., Mousavi, S.F. (2008). Estimation of moisture in maize leaf by measuring leaf dielectric constant. International Journal of Agriculture \& Biology, 10(1): 66-68.

[20] Mander, G., Arora, M. (2014). Design of capacitive sensor for monitoring moisture Content of soil and analysis of analog voltage with variability in moisture. Proceedings of 2014 Recent Advances in Engineering and Computational Sciences (RAECS), pp. 1-5. https://doi.org/10.1109/RAECS.2014.6799646

[21] Soulis, K.S., Elmaloglou, S., Dercas, N. (2014). Investigating the effects of soil moisture sensors positioning and accuracy on soil moisture based drip irrigation scheduling systems. Agricultural Water Management, 148: 258-268. https://doi.org/10.1016/j.agwat.2014.10.015

[22] Jéan du Plessis (2003). Maize production. Department of Agriculture and obtainable from Resource Centre Directorate Agricultural Information Services, Private Bag X144, Pretoria, 0001 South Africa, www.nda.agric.za/publications.

[23] Hatfield, J.L., Prueger, J.H. (2015). Temperature extremes: Effect on plant growth and development. Weather and Climate Extremes, 10(A): 4-10. https://doi.org/10.1016/j.wace.2015.08.001

[24] Shamshiri, R.R., Jones, J.W., Thorp, K.R., Ahmad, D., Man, H.C., Taheri, S. (2018). Review of optimum temperature, humidity, and vapor pressure deficit for microclimate evaluation and control in greenhouse cultivation of tomato: A review. International Agrophysics, 32(2): 287-302. https://doi.org/10.1515/intag-2017-0005

[25] Fan CFM Calculator \& Chart. Industrial Fans Direct. www.industrialfansdirect.com/pages/exhaust-fan-cfmcalculator.

[26] DC Fan Catalog (2012). Protechnic Electric Co., Ltd. 